\title{
Diagnosis of Helicobacter pylori Infection
}

\author{
Taweesak Tongtawee ${ }^{1,4 *}$, Soraya Kaewpitoon ${ }^{2,4}$, Natthawut Kaewpitoon ${ }^{5,6}$, \\ Chavaboon Dechsukhum ${ }^{3,4}$, Wilairat Leeanansaksiri' ${ }^{5}$, Ryan A Loyd ${ }^{2,4}$, Likit \\ Matrakool $^{1,4}$, Sukij Panpimanmas ${ }^{1,4}$
}

\begin{abstract}
Helicobacter pylori infection plays an important role in the pathogenesis of chronic gastritis, peptic ulcer disease and gastric malignancy. A diagnosis of infection is thus an important part of a treatment strategy of many gastrointestinal tract diseases. Many diagnostic tests are available but all have some limitations in different clinical situations and laboratory settings. A single gold standard cannot available, but be used for diagnosis of Helicobacter pylori infection in daily clinical practice in all areas, so several techniques have been developed to give reliable results, especially focusing on real time endoscopic features. The narrow band imaging system (NBI) and high resolution endoscopy are imaging techniques for enhanced visualization of infected mucosa and premalignant gastric lesions. The aim of this article is to review the current diagnostic options and possible future developments detection of Helicobacter pylori infection.
\end{abstract}

Keywords: Diagnosis - Helicobacter pylori infection - methodology - invasive/non-invasive

Asian Pac J Cancer Prev, 17 (4), 1631-1635

\section{Introduction}

Helicobacter pylori infection is one main cause of gastric cancer development due to chronic infection and inflammation process. A diagnosis of Helicobacter pylori infection is an important part of the treatment plan. The diagnoses of Helicobacter pylori infection are usually divided into invasive and noninvasive test. Invasive tests include diagnostic endoscopy, bacterial histology, rapid urease test from gastric mucosa, bacterial culture and molecular genetic (PCR) methods.

Noninvasive tests included urea breath test (UBT), stool antigen test, serological and molecular genetic method (PCR). European guidelines indicate that at least 2 different tests are necessary to make the diagnosis of Helicobacter pylori infection (A Bah et al., 1995). A recent study from India (Patel et al., 2014) attempted to define the "gold standard" of diagnostic tests to determine Helicobacter pylori infection status. The results show that, both sensitivity and specificity of nested PCR have been reported to be $100 \%$, but the PCR seems to not be feasible in daily clinical practice due to cost and availability. Recent advances development of high resolution endoscopy with NBI in the past decade. The recent Kyoto global consensus report on Helicobacter pylori gastritis suggested that atrophic mucosa and intestinal metaplasia can be accurately detected by image-enhanced endoscopy, after appropriate training (Kentaro et al., 2015). In this article, we review the current diagnostic test and its developments of new methods that can be applied to use in daily clinical practices depend on different clinical situations.

\section{Invasive Tests and Endoscopic Diagnosis}

Conventional white light source endoscopy is usually routinely endoscopic examination in daily clinical practice. This is usually performed to diagnose Helicobacter pylori infection and other disease in the upper gastrointestinal tract and get the tissue sampling for histology and rapid urease test. Several studies have been proposed in recent years.

In a multicenter prospective study of 225 patients in Japan (Kato et al., 2013), the result suggested that an endoscopic diagnosis of Helicobacter pylori infection in gastric mucosa by conventional endoscopy and the IC method is mostly possible, the ROC curve for Helicobacter pylori infection of conventional endoscopy was 0.811 in the corpus and 0.707 in the antrum $(\mathrm{P}=0.006)$. The report from Japan about accuracy of endoscopic diagnosis of Helicobacter pylori infection, according to level of endoscopic experience and the effect of training (Watanabe et al., 2013). The result shows that, the diagnostic yield of endoscopic diagnosis was high for Helicobacter pylori uninfected cases, but was lower for Helicobacter pylori eradicated cases $(88.9 \%$ for Helicobacter pylori

${ }^{1}$ Department of Surgery, ${ }^{2}$ Family Medicine and Community Medicine, ${ }^{3}$ School of Pathology, Institute of Medicine, ${ }^{5}$ Parasite Research Unit, ${ }^{6}$ School of Microbiology, Institute of Science, ${ }^{4}$ Suranaree University of Technology Hospital, Suranaree University of Technology, Nakhon Ratchasima,Thailand*For correspondence: taweesak.t@sut.ac.th 
uninfected, $62.1 \%$ for Helicobacter pylori infected, and $55.8 \%$ for Helicobacter pylori eradicated). They conclude that, daily training on endoscopic findings improved the low diagnostic yield. The high resolution with Narrow Band Imaging (NBI) endoscopy has been developed. Kyoto global consensus report on Helicobacter pylori gastritis (Kentaro Sugano et al., 2015). They conclude that, Atrophic mucosa and intestinal metaplasia can be accurately detected by image-enhanced endoscopy, after appropriate training (Grade of recommendation: strong). A recent our study for Conventional Narrow Band Imaging gastroscopy (C-NBI) in 2015, the results show good efficacy for diagnosis of Helicobacter pylori infection and good correlation to the histopathology of the gastric mucosa (Taweesak et al., 2015). According to problem during tissue sampling. A recent our study in 2015 by using "Site Specific Biopsy". We randomized a total 500 patients who underwent gastroscopy for investigation of dyspeptic symptoms. The results show that, "Site Specific Biopsy" was more effective than the standard biopsy in terms of both Helicobacter pylori infection status and premalignant gastric mucosa detection (sensitivity, specificity, positive and negative predictive values for predicting Helicobacter pylori positivity were $95.4 \%, 97.3 \%, 98.8 \%$ and $90.0 \%$, respectively $[\mathrm{P}<0.01]$ ) (Taweesak et al., 2015). The need for proper training in high resolution endoscopy and NBI technique was also emphasized for improved accuracy of the Helicobacter pylori infection and premalignant gastric mucosa in daily clinical practice.

\section{Histology}

Positive histology is still a standard diagnosis for Helicobacter pylori infection included gastric mucosal change after infected. The number and location of the biopsy are major problem for the endoscopist during tissue sampling. Recommendation from Sydney system classification, Biopsies were taken from five standardized intragastric locations. 1: antrum (four quadrants), 2: incisura angularis, 3 : corpus greater curvature, 4: corpus lesser curvature, 5: cardia (CM den Hoed et al., 2013). However, in daily clinical practice, five standardized intragastric biopsies seem to not be feasible, because it takes more examination time and increase workload for pathologists. A recent study from Thailand in 2015, the result shows that, "Site Specific Biopsy" by using C-NBI gastroscopy improves the Helicobacter pylori infection and pre-malignant gastric mucosa in daily clinical practice
(Taweesak et al., 2015). According to staining Helicobacter pylori morphology and consequence after infection on gastric mucosa specimens. Several studies have been proposed. A recent study from US about appropriate use of special stains for identifying Helicobacter pylori infection, the results show that, ancillary stains are appropriate when biopsies show chronic, or chronic active, gastritis without detectable Helicobacter pylori in hematoxylin and eosin-stained sections, but performing them "up front" on all gastric biopsies is generally unnecessary (Batts et al., 2013). A recent study from Europe about pre-malignant gastric mucosa in term of Interobserver variation in assessment of gastric premalignant lesions, they concluded, the agreement was substantially higher for intestinal metaplasia than for atrophy (Leja et al., 2013). A recent study from China about gastric cancer patients and Helicobacter pylori infection in term of survival analysis, the results show that, Helicobacter pylori infection could be an indicator for prognosis of gastric cancer patients $(\mathrm{Li}$ et al., 2013)

\section{Bacterial culture}

A study about Biofilm and Helicobacter pylori have been proposed in 2014, they conclude that, the ability of Helicobacter pylori to form biofilm may be important for surviving under stress conditions or in the spread of the infection among humans, mainly through natural water sources and water distribution systems (Garcia et al., 2014). A study of proper system for Helicobacter pylori growth in 2013, the results show that, the use of BACTEC FX system significantly shortens the time needed for culturing, which makes the system more efficient in the identification of Helicobacter pylori (Peretz et al., 2013). A recent study about preservation the bacteria in 2013, they report the recovery of Helicobacter pylori from gastric tissue cryopreserved $\left(-70^{\circ} \mathrm{C}\right)$ for more than 10 years (Seo et al., 2013).

\section{Molecular method}

Several studies have been proposed in recent years. A study from India by Patel et al. (2014). They report attempts to define the "gold standard" of diagnostic tests to determine Helicobacter pylori infection status. The results show that, both sensitivity and specificity of nested PCR have been reported to be $100 \%$. The real-time PCR has been developed. A study about efficacy of real-time

Table 1. Diagnostic Accuracy of Five Different Stool Antigen Tests for the Diagnosis of Helicobacter Pylori Infection

\begin{tabular}{|c|c|c|c|c|c|}
\hline Type of stool antigen tests & Sensitivity & specificity & PPV & NPV & Accuracy \\
\hline \multicolumn{6}{|l|}{ ELISA } \\
\hline $\begin{array}{l}\text { Premium Platinum HpSA Plus (Meridian Biosciences, Cincinnati, } \\
\text { OH, USA) }\end{array}$ & $92.20 \%$ & $94.40 \%$ & $93.30 \%$ & $93.60 \%$ & $93.40 \%$ \\
\hline HP-Ag-EIA (Dia-Pro Diagnostic Bioprobes, Milan, Italy) & $48.90 \%$ & $88.90 \%$ & $78.60 \%$ & $67.60 \%$ & $71 \%$ \\
\hline \multicolumn{6}{|l|}{ Immunochromatographic test (ICT) } \\
\hline Immunocard STAT!HpSA (Meridian Biosciences) & $68.90 \%$ & $92.60 \%$ & $88.60 \%$ & $78.10 \%$ & $81.80 \%$ \\
\hline H. pylori fecal antigen test(Vegal Farmaceutica, Madrid, Spain) & $78.90 \%$ & $87.00 \%$ & $83.50 \%$ & $83.20 \%$ & $83.30 \%$ \\
\hline One-Step H. pylori Antigena(Acon Lab, San Diego, CA, USA) & $86.70 \%$ & $88.90 \%$ & $86.70 \%$ & $88.90 \%$ & $88 \%$ \\
\hline
\end{tabular}

PPV $=$ Positive Predictive Value; NPV = Negative Predictive Value 
PCR method for Clarithromycin resistance, the results show that, real-time PCR method by using LightCycler thermocycler is a good technique for detection drug resistant (Oleastro M et al., 2003: Cerqueira Let al., 2013). A study about new technique for improved detection of Helicobacter pylori DNA in formalin-fixed, paraffinembedded (FFPE) tissue, the results show that, laser capture microdissection (LCM) is a good technique for detecting Helicobacter pylori infection (Rabelo-Goncalves et al., 2013). According to high prevalence of Helicobacter pylori resistance to clarithromycin in many countries. A recent study from the Northeast of Thailand, the results show that, high rate of Helicobacter pylori resistance to clarithromycin. Mixed of wild type and mutant genotype is the most common mutant phenotype [(Wild type, A2143/2142A (Susceptible) Mutation + A2143/2142CG (Resistance)], therefore the use of clarithromycin-based triple therapy not advisable as an empiric first-line regimen for Helicobacter pylori eradication in the northeast region of Thailand (Taweesak et al., 2015). Tailored triple therapy is the treatment regimen for improving Helicobacter pylori eradication rate in area with high drug resistant. Recent 2 RCT in Thailand about tailored triple therapy $(n=500)$, the results show that, adding probiotics before or before and after tailoring treatment can improve Helicobacter pylori eradication rates (Taweesak et al., 2015).

\section{Noninvasive Tests and Urea Breath Test}

UBT is still the standard diagnostic tool for detecting Helicobacter pylori eradication after treatment. A recent study in 2014, the results show that, Incomplete/nonresolution of ${ }^{(14)} \mathrm{C}$-urea capsule in the stomach during the phase of breath collections appears to decrease sensitivity of encapsulated ${ }^{(14)} \mathrm{C}$-UBT as compared to nonencapsulated protocol for detection of Helicobacter pylori infection [sensitivity, 97.2\% versus $91.8 \%$, respectively, after 15 minutes in a series of 100 dyspeptic patients] (Pathak et al., 2014).

\section{Stool Antigen Test}

Comparison of the diagnostic accuracy of five different stool antigen tests for the diagnosis of Helicobacter pylori infection in $2013(n=198)$. Stool specimens for HpSA testing were also collected; the results show in Table 1.they conclude that, the Premier Platinum HpSA plus EIA test was determined to be the most accurate stool test for diagnosing Helicobacter pylori infections in adult dyspeptic patients (Korkmaz et al., 2013).

A review stool antigen tests for the management of Helicobacter pylori infection in 2013. They conclude that, SAT are also useful for the diagnosis of Helicobacter pylori infection in children and post gastric surgery patients. Temperature and the interval between stool sample collection and measurement also affect the results of the SAT (Shimoyama et al., 2013).

A recent study about the accuracy of fecal occult blood test and Helicobacter pylori stool antigen test for detection of upper gastrointestinal lesions from China in $2013(n=3172)$. They suggest that, The Helicobacter pylori stool antigen test is more accurate than the guaiacbased test in the screening of upper gastrointestinal lesions in a population with high prevalence of Helicobacter pylori infection and upper gastrointestinal lesions. It was concluded that it is applicable to add the Helicobacter pylori antigen test to the immunochemical test for pan detection (Lee et al., 2013).

\section{Antibody Tests}

The study from France in $2013(\mathrm{n}=500)$, they compare antibody test for diagnosis Helicobacter pylori infection. The results show that, sensitivity and specificity of $97.6 \%$ and $96.2 \%$, respectively, compared to histology for diagnosis Helicobacter pylori infection (Table 2). They conclude that, the recom Line assay provides a good valuable tool for the diagnosis of Helicobacter pylori infection (Formichella et al., 2013; Burucoa et al., 2013).

A recent study from Iran in 2013 about antigenic proteins of Helicobacter pylori of potential diagnostic value. They conclude that, CagI $(25 \mathrm{kDa})$, urease $\mathrm{G}$ accessory protein $(25 \mathrm{kDa})$, UreB $(63 \mathrm{kDa})$ and proline/ pyrroline- 5-carboxylate dehydrogenase (118 KDa). These identified proteins, singly and/or in combinations, may be useful for diagnosis of Helicobacter pylori infection in patients (sensitivity and specificity (98$100 \%$ ) (Khalilpour, 2013). A study from Iran about seroreactivity to Helicobacter pylori antigens as a risk indicator of gastric cancer in 2013, the results show that, seroreactivity to Helicobacter pylori low $(35 \mathrm{kDa})$ and high $(116 \mathrm{kDa} / 89 \mathrm{kDa})$ molecular weight antigens were respectively revealed as protective and risk indicators for gastric cancer (Karami, 2013).

\section{Non-Invasive Diagnosis of Premalignant Gastric Lesions}

Several studies about pepsinogen I and II and their ratio as predictors of atrophy from Iran, Turkey, Italy in 2013-2014.They conclude that, insensitive for predicting premalignant gastric lesion in Helicobacter pylori infected patients (Hosseini et al., 2013; Yakut et al., 2013; Masci et al., 2014). Two studies about the role of toll-like receptor 4 (TLR 4) for predictive premalignant gastric lesion (Yakut et al., 2013; Masci et al., 2104). The concluding that, both miR-106b and miR-21 were found as markers of increased risk for gastric precancerous lesion after Helicobacter pylori eradication.

Table 2. Performances of Serological Tests for the 500 Cases Included in the Study

\begin{tabular}{lccc}
\hline \multirow{2}{*}{ Parameter } & \multicolumn{3}{c}{ Performance [\% (no./total)] } \\
\cline { 2 - 4 } & recomLine & recomWell & Immunoblot \\
\hline \multirow{2}{*}{ Sensitivity } & 97.6 & 86.2 & 85.2 \\
& $(205 / 210)$ & $(181 / 210)$ & $(179 / 210)$ \\
Specificity & 96.2 & 95.5 & 97.9 \\
& $(279 / 290)$ & $(277 / 290)$ & $(284 / 290)$ \\
PPV & 94.5 & 92.7 & 96.4 \\
NPV & 98.4 & 91.2 & 90.8 \\
\hline
\end{tabular}

Asian Pacific Journal of Cancer Prevention, Vol 17, 2016 
Table 3. Appropriate Diagnostic Methods for Helicobacter Pylori Infection in Difference Clinical Situation

\begin{tabular}{|c|c|c|c|c|}
\hline Diagnostic methods & $\begin{array}{l}\text { Gastroduodenal } \\
\text { bleeding }\end{array}$ & $\begin{array}{c}\text { Post } \\
\text { gastrectomy }\end{array}$ & $\begin{array}{c}\text { Post eradication } \\
\text { therapy }\end{array}$ & Application \\
\hline Rapid urease test & & $\mathrm{x}$ & & \\
\hline Histology & & $\mathrm{x}$ & & \\
\hline Culture & & & & Antibiotic sensitivity \\
\hline Polymerase chain reaction & $\mathrm{x}$ & & $\mathrm{x}$ & $\begin{array}{c}\text { Antibiotic sensitivity, Virulence factors, } \\
\text { Environmental/oral sample }\end{array}$ \\
\hline Urea breath test & $\mathrm{x}$ & & $\mathrm{x}$ & \\
\hline Stool antigen test & & & $\mathrm{x}$ & Pediatric patient \\
\hline Serology & $\mathrm{X}$ & & $\mathrm{x}$ & Virulence factors \\
\hline
\end{tabular}

\section{Conclusion}

The new endoscopic imaging to be improves real time diagnostic accuracy. High resolution endoscopy with NBI is the high accuracy to diagnose Helicobacter pylori infection and premalignant gastric mucosa. Limitation of the endoscopist, equipment and take more time when compared with conventional endoscopy, so high resolution endoscopy unfeasible in daily clinical practice. There are continuous attempts to improve the existing diagnostic methods or to evaluate their use daily clinical practice. The proper diagnostic methods for Helicobacter pylori infection are summarized in Table 3 (Wang et al., 2014). The single standard test does not recommend, the proper test to detect Helicobacter pylori infection depends on the prevalence and strains of Helicobacter pylori includes different clinical circumstances of each patient. Two or more tests are good diagnostic strategy in routine clinical practice to achieve the most accurate result.

\section{References}

A Bah, E Saraga, D Armstrong, et al (1995). "Endoscopic features of Helicobacter pylori-related gastritis". Endoscopy, 27, 593-6.

Batts KP, Ketover S, Kakar S, et al (2013). Appropriate use of special stains for identifying Helicobacter pylori: recommendations from the rodger $\mathrm{c}$. haggitt gastrointestinal pathology society. Am J Surg Pathol, 37, 12-22.

Burucoa C, Delchier JC, Courillon-Mallet A, et al (2013). Comparative evaluation of 29 commercial Helicobacter pylori serological kits. Helicobacter, 18, 169-79.

Cerqueira L, Fernandes RM, Ferreira RM, et al (2013). Validation of a fluorescence in situ hybridization method using peptide nucleic acid probes for detection of Helicobacter pylori clarithromycin resistance in gastric biopsy specimens. J Clin Microbiol, 51, 1887-93.

CM den Hoed, IL Holster, LG Capelle, et al (2013). Follow-up of premalignant lesions in patients at risk for progression to gastric cancer. Endoscopy, 45, 249-56.

Formichella L, Romberg L, Bolz C, et al (2013). A novel line immunoassay based on recombinant virulence factors enables highly specific and sensitive serologic diagnosis of Helicobacter pylori infection. Clin Vaccine Immunol, 20, 1703-10.

Garcia A, Salas-Jara MJ, Herrera C, et al (2014). Biofilm and Helicobacter pylori: from environment to human host. World J Gastroenterol, 20, 5632-8.

Hosseini M, Amoueian S, Attaranzadeh A, et al (2013). Serum gastrin 17, pepsinogen I and pepsinogen II in atrophic gastritis patients living in North-East of Iran. J Res Med
Sci, 18, 225-9.

Karami N, Talebkhan Y, Saberi S, et al (2013). Seroreactivity to Helicobacter pylori antigens as a risk indicator of gastric cancer. Asian Pac J Cancer Prev, 14, 1813-7.

Kato T, Yagi N, Kamada T, et al (2013). Diagnosis of Helicobacter pylori infection in gastric mucosa by endoscopic features: a multicenter prospective study. Dig Endosc, 25, 508-18.

Kentaro Sugano, Jan Tack, Ernst J Kuipers, et al (2015). Kyoto global consensus report on Helicobacter pylori gastritis. Gut, 64, 1353- 67.

Khalilpour A, Santhanam A, Wei LC, et al (2013). Antigenic proteins of Helicobacter pylori of potential diagnostic value. Asian Pac J Cancer Prev, 14, 1635-42.

Korkmaz H, Kesli R, Karabagli P, et al (2013). Comparison of the diagnostic accuracy of five different stool antigen tests for the diagnosis of Helicobacter pylori infection. Helicobacter, 18, 384-91.

Leja M, Funka K, Janciauskas D, et al (2013). Interobserver variation in assessment of gastric premalignant lesions: higher agreement for intestinal metaplasia than for atrophy. Eur J Gastroenterol Hepatol, 25, 694-9.

Lee YC, Chiu HM, Chiang TH, et al (2013). Accuracy of fecal occult blood test and Helicobacter pylori stool antigen test for detection of upper gastrointestinal lesions. $B M J, 3,7-10$.

Li G, Wang Z, Wang Z, et al (2013). Gastric cancer patients with Helicobacter pylori infection have a poor prognosis. J Surg Oncol, 108, 421-6.

Masci E, Pellicano R, Mangiavillano B, et al (2014). Gastro Panel(R) test for non-invasive diagnosis of atrophic gastritis in patients with dyspepsia. Minerva Gastroenterol Dietol, 60, 79-83.

Oleastro M, Menard A, Santos A, et al (2003). Real-time PCR assay for rapid and accurate detection of point mutations conferring resistance to clarithromycin in Helicobacter pylori. J Clin Microbiol, 41, 397- 402.

Patel SK, Pratap CB, Jain AK, et al (2014). Diagnosis of Helicobacter pylori: What should be the gold standard?. World J Gastroenterol, 20, 12847-59.

Pathak CM, Kaur B, Bhasin DK, et al (2014). Comparison of encapsulated versus nonencapsulated ${ }^{(14)} \mathrm{C}$-urea breath test for the detection of Helicobacter pylori infection: a scintigraphy study. Helicobacter, 19, 116-23.

Peretz A, On A, Koiefman H, et al (2013). BACTEC FX system as a tool for culturing gastric biopsies and Helicobacter pylori diagnosis. Eur J Clin Microbiol Infect Dis, 32, 1541-3.

Rabelo-Goncalves EM, Sgardioli IC, Lopes-Cendes I, et al (2013). Improved detection of Helicobacter pylori DNA in formalin-fixed paraffin-embedded (FFPE) tissue of patients with hepatocellular carcinoma using laser capture microdissection (LCM). Helicobacter, 18, 244-5.

Seo JH, Youn HS, Goo MJ, et al (2013). Recovery of Helicobacter pylori from gastric tissue cryopreserved for more than 10 years. Helicobacter, 18, 167-8. 
Shimoyama T (2013). Stool antigen tests for the management of Helicobacter pylori infection. World J Gastroenterol, 19, 8188-91.

Sugano K, Tack J, Kuipers EJ, et al (2015). Kyoto global consensus report on Helicobacter pylori gastritis. Gut, 64, 1353-67

Taweesak T, Soraya K, Natthawut K, et al (2015). Correlation between gastric mucosal morphologic patterns and histopathological severity of helicobacter pylori associated gastritis using conventional narrow band imaging gastroscopy. Biomed Res Int, 7, 42-8.

Taweesak T, Chavaboon D, Wilairat L, et al (2015). Improved Detection of Helicobacter pylori Infection and Premalignant Gastric Mucosa Using “Site Specific Biopsy”: A Randomized Control Clinical Trial. Asian Pac J Cancer Prev, 16, 8487 90.

Taweesak T, Chavaboon D, Likit M, et al (2015). High prevalence of Helicobacter pylori resistance to clarithromycin: a hospital-based cross-sectional study in nakhon ratchasima province, northeast of Thailand. Asian Pac J Cancer Prev, 16, 8281-85.

Taweesak T, Chavaboon D, Wilairat L, et al (2015). Improved Helicobacter pylori eradication rate of tailored triple therapy by adding lactobacillus delbrueckii and Streptococcus thermophilus in Northeast Region of Thailand: a prospective randomized controlled clinical Trial. Gastro Res Prac, 1, 7-12.

Taweesak T, Chavaboon D, Wilairat L, et al (2015). Effect of pretreatment with lactobacillus delbrueckii and streptococcus thermophillus on tailored triple therapy for Helicobacter pylori eradication: a prospective randomized controlled clinical Trial. Asian Pac J Cancer Prev, 16, 4885-90.

Watanabe K, Nagata N, Shimbo T, et al (2013). Accuracy of endoscopic diagnosis of Helicobacter pylori infection according to level of endoscopic experience and the effect of training. BMC Gastroenterol, 13, 128.

Yakut M, Ormeci N, Erdal H, et al (2013). The association between precancerous gastric lesions and serum pepsinogens, serum gastrin, vascular endothelial growth factor, serum interleukin-1 Beta, serum toll-like receptor-4 levels and Helicobacter pylori Cag A status. Clin Res Hepatol Gastroenterol, 37, 302-11. 